\title{
Potencial de genótipos de feijão-caupi para o mercado de vagens e grãos verdes
}

\author{
Jaqueline Luz Moura Sousa(1), Maurisrael de Moura Rocha(2), Kaesel Jackson Damasceno e Silva(2), \\ Adão Cabral das Neves ${ }^{(2)}$ e Raylson Rodrigues de Sousa ${ }^{(1)}$
}

\begin{abstract}
(1)Universidade Federal do Piauí, Campus Universitário Ministro Petrônio Portella, Bairro Ininga, CEP 64049-550 Teresina, PI, Brasil. E-mail: jaquelineluz01@hotmail.com, rayr-80@hotmail.com ${ }^{(2)}$ Embrapa Meio-Norte, Avenida Duque de Caxias, no 5.650, Buenos Aires, CEP 64006-220 Teresina, PI, Brasil. E-mail: maurisrael.rocha@embrapa.br, kaesel.damasceno@embrapa.br, adao.neves@embrapa.br
\end{abstract}

Resumo - O objetivo deste trabalho foi avaliar a variabilidade de genótipos de feijão-caupi e selecionar aqueles com potencial para o mercado de vagens e grãos verdes. Em 2012, foram avaliados 16 genótipos em dois experimentos (sequeiro e irrigado), em delineamento de blocos ao acaso, com quatro repetições. Foram avaliados os caracteres: número de dias para o início da floração, comprimento de vagem verde, número de grãos por vagem verde, massa de cem grãos verdes, produtividade de vagens verdes, produtividade de grãos verdes e índice de grãos verdes. A maioria dos caracteres apresentou diferenças quanto ao ambiente de cultivo, mas a resposta dos genótipos às variações ambientais foi similar. Os genótipos, sob irrigação, apresentaram produtividade de vagens e grãos verdes similar à das testemunhas. A cultivar Azulão-MS, em sequeiro, apresentou alto potencial para a produção de vagens verdes, no entanto, com baixa relação grão verde/vagem verde. A cultivar BRS Tumucumaque apresenta potencial para a produtividade de grãos verdes em sequeiro, enquanto a linhagem MNC00-595F-27 produz mais em condições de irrigação.

Termos para indexação: Vigna unguiculata, feijão verde, irrigação, sequeiro.

\section{Potential of genotypes for fresh pod and fresh-shelled cowpea market}

\begin{abstract}
The objective of this work was to evaluate the variability of cowpea genotypes and to select those with potential for fresh pod and fresh-shelled cowpea market. In 2012, 16 genotypes were evaluated in two experiments (rainfed and irrigated), which were conducted in a randomized complete block design with four replicates. The following traits were evaluated: number of days for flowering start, fresh pod length, number of seed per fresh pod, weight of hundred fresh grains, fresh pod yield, fresh grain yield, and fresh grain index. Most of the traits showed differences according to the growth environment, but the response of genotypes to environmental variations was similar. Genotypes under irrigation conditions showed fresh pod and seed yield similar to the ones of the checks. The Azulão-MS cultivar under rainfed conditions showed a high potential for fresh pod yield, however, it had a low relationship fresh-shelled seed/fresh pod. The BRS Tumucumaque cultivar has potential for fresh seed yield under rainfed conditions, while the MNC00-595F-27 line is more productive under irrigation.
\end{abstract}

Index terms: Vigna unguiculata, immature cowpea, irrigation, rainfed.

\section{Introdução}

O feijão-caupi [Vigna unguiculata (L.) Walp.] apresenta uma grande variabilidade genética que o torna versátil e é usado para várias finalidades e em diversos sistemas de produção. No Brasil, há três segmentos de mercado para essa cultura: grãos secos, feijão verde (vagem e grãos verdes) e sementes. Esses dois últimos são mercados crescentes (Freire Filho, 2011). O termo "verde" se refere mais ao estádio em que a vagem é colhida do que propriamente à cor dos grãos.

$\mathrm{O}$ feijão verde corresponde à fase em que as vagens do feijão-caupi estão próximas da maturação, quando elas param de acumular fotossintatos, e os grãos apresentam umidade em torno de 60 a 70\% (Souza et al., 2007). Nesse estádio, o teor de proteína nos grãos é, em média, de 9,65 g $100 \mathrm{~g}^{-1}$, o de fibra alimentar é de

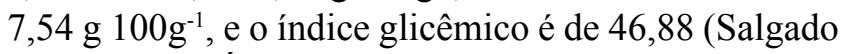
et al., 2005). É um produto que tem grande potencial para a expansão do consumo, como também para $o$ processamento industrial (Freire Filho et al., 2007) nas formas de enlatamento, resfriamento e congelamento (Freire Filho, 2011; Silva et al., 2013).

O mercado do feijão verde é de grande importância para a região Nordeste e muitas capitais das regiões Norte, Sudeste e Centro-Oeste do Brasil. O cultivo de 
feijão-caupi, para uso como vagens e grãos verdes, tem sido realizado predominantemente por pequenos agricultores, em condição de sequeiro, com pouca utilização de tecnologia. No entanto, tem aumentado seu cultivo em condições de irrigação, por agricultores empresariais que utilizam maior nível de tecnologia. Assim, no processo de seleção para o mercado de vagens e grãos verdes, devem-se também identificar genótipos com boa resposta produtiva tanto em sequeiro quanto sob irrigação. Alguns trabalhos têm avaliado a resposta produtiva do feijão verde em ambas as condições de cultivo (Ramos et al., 2012; Rocha et al., 2012; Silva et al., 2013).

Os esforços para o melhoramento do feijão-caupi têm sido concentrados no estudo de parâmetros genéticos de caracteres mais relacionados ao mercado de vagens e grãos verdes, como: comprimento de vagem, tamanho de grão, índice de grãos, facilidade de debulha da vagem, produtividade de vagens e de grãos (Andrade et al., 2010; Rocha et al., 2012; Silva et al., 2013), qualidade nutricional e culinária do grão (Benevides et al., 2013) e processamento pós colheita do grão (Furtunato et al., 2000; Lima et al., 2000, 2003; Benevides et al., 2013).

Para o mercado de feijão verde, os agricultores têm utilizado genótipos com grãos de várias cores (em que predomina a classe comercial branca) e também os tipos sempre-verde, canapu, mulato, azulão e corujinha. Com exceção da cor branca, nas demais cores, à medida que a vagem ou o grão debulhado vai perdendo a umidade, o grão vai adquirindo a cor natural de grão seco, ou seja, vai escurecendo e isso deprecia o produto. Assim, o melhoramento tem investido na subclasse comercial verde (grãos de tegumento e cotilédone verde), por apresentarem maior potencial para a preservação da cor verde após a colheita (Freire Filho et al., 2002, 2007).

O objetivo deste trabalho foi avaliar a variabilidade de genótipos de feijão-caupi e selecionar aqueles com potencial para o mercado de vagens e grãos verdes.

\section{Material e Métodos}

Dois experimentos foram realizados no ano de 2012, no campo experimental da Embrapa Meio-Norte, no Município de Teresina, PI, situado a $05^{\circ} 05^{\prime} \mathrm{S}, 42^{\circ} 48^{\prime} \mathrm{W}$ e a $72 \mathrm{~m}$ de altitude, com clima tropical subúmido quente, do tipo Aw, de acordo com a classificação de
Köppen-Geiger. O primeiro experimento foi realizado em sequeiro, entre março e maio, enquanto o segundo, irrigado, entre agosto e outubro. A pluviosidade total, ocorrida no período de condução do ensaio de sequeiro, foi de $242,20 \mathrm{~mm}$. O solo da área experimental foi classificado como Argissolo Amarelo distrófico, com textura franco-arenosa, e apresentou os seguintes atributos químicos na camada de $0-20 \mathrm{~cm}: \mathrm{pH}$ em água, 5,94; $\mathrm{P}, 31,48 \mathrm{mg} \mathrm{dm}^{-3} ; \mathrm{K}, 0,18 \mathrm{cmol}_{\mathrm{c}} \mathrm{dm}^{-3}$; $\mathrm{Ca}, 1,52 \mathrm{cmol}_{\mathrm{c}} \mathrm{dm}^{-3} ; \mathrm{Mg}, 0,39 \mathrm{cmol}_{\mathrm{c}} \mathrm{dm}^{-3} ; \mathrm{H}+\mathrm{Al}$, $1,57 \mathrm{cmol}_{\mathrm{c}} \mathrm{dm}^{-3} ; \mathrm{N}, 0,6 \mathrm{~g} \mathrm{~kg}^{-1}$; matéria orgânica, 12,2 dag $\mathrm{kg}^{-1}$; e CTC, 3,66.

Foram avaliados 16 genótipos de feijão-caupi, que incluíram linhagens e cultivares, pertencentes às subclasses comerciais branca, canapu, azulão e verde, oriundos do Banco Ativo de Germoplasma e do Programa de Melhoramento de Feijão-caupi da Embrapa Meio-Norte (Tabela 1). Três cultivares locais (Vagem Roxa-THE, Azulão-MS e Sempre Verde-CE), comercializadas como feijão verde, foram utilizadas como testemunhas.

O experimento foi realizado em delineamento experimental de blocos completos ao acaso, com quatro repetições. A parcela experimental tinha as dimensões de $3,2 \times 5,0 \mathrm{~m}$ e foi constituída por quatro fileiras de 5,0 m de comprimento, tendo como área útil as duas fileiras centrais. Utilizou-se o espaçamento de $0,80 \mathrm{~m}$ entre fileiras e de $0,25 \mathrm{~m}$ entre covas dentro da fileira, o que resultou em 20 covas por fileira. Quatro sementes por cova foram semeadas e, aos 15 dias após a semeadura, foi realizado um desbaste, tendo-se deixado duas plantas por cova.

No preparo do solo de ambas as áreas experimentais, utilizou-se uma aração, seguida de uma gradagem. Os tratos culturais consistiram da aplicação de herbicida de pré-emergência à base de s-metolacloro $\left(1 \mathrm{~L} \mathrm{ha}^{-1}\right)$ e de capinas manuais complementares, para o controle de ervas daninhas. Após o plantio, realizouse o controle de insetos ao início do ciclo (pulgões), à floração (tripes) e ao início da frutificação (lagartas e percevejos), com uso de inseticidas à base de dimetoato (1 L ha-1) e thiamethoxam (100 $\left.\mathrm{g} \mathrm{ha}^{-1}\right)$.

No experimento realizado com irrigação, utilizou-se aspersão convencional, com uma lâmina d'água média de $20 \mathrm{~mm}$, no período de duas horas, com turno de rega de cinco dias. A colheita foi conduzida manualmente, sempre que as vagens estavam no ponto de maturação 
para comercialização como feijão verde, quando os grãos apresentavam $60-70 \%$ de umidade.

Avaliaram-se os seguintes caracteres: número de dias para o início da floração (NDIF), comprimento de vagem verde (CVV), número de grãos por vagem verde (NGVV), massa de cem grãos verdes (M100GV), produtividade de vagens verdes (PVV), produtividade de grãos verdes (PGV) e índice de grãos verdes (IGV). O IGV foi calculado como a razão entre a massa do grão verde e a massa da vagem verde. Os caracteres CVV, NGVV, M100GV e IGV foram mensurados com base em uma amostra de 10 vagens, retiradas aleatoriamente da área útil da parcela.

As análises de variância individual e conjunta foram realizadas para todos os caracteres. Para a análise de variância individual, utilizou-se o modelo

Tabela 1. Genótipos de feijão-caupi, avaliados quanto à característica feijão verde, com suas respectivas origens e subclasses comerciais.

\begin{tabular}{|c|c|c|c|}
\hline $\mathrm{N}^{\circ}$ & Genótipo & Origem & $\begin{array}{l}\text { Subclasse } \\
\text { comercial }\end{array}$ \\
\hline 1 & $\mathrm{MNC} 00-303-09 \mathrm{E}^{(1)}$ & $\begin{array}{c}\text { (Capela x Costelão) } \mathrm{x} \\
\text { Costelão }\end{array}$ & Branca \\
\hline 2 & $\mathrm{MNC} 00-595 \mathrm{~F}-2^{(1)}$ & $\begin{array}{c}\text { BR2-Bragança x } \\
\text { GV-10-91-1-1 }\end{array}$ & Verde \\
\hline 3 & $\mathrm{MNC} 00-595 \mathrm{~F}-27^{(1)}$ & $\begin{array}{c}\text { BR2-Bragança x } \\
\text { GV-10-91-1-1 }\end{array}$ & Verde \\
\hline 4 & MNC05-835B-15 ${ }^{(1)}$ & $\begin{array}{l}\text { MNC00-599F-2 x } \\
\text { MNC99-537F-14-2 }\end{array}$ & Verde \\
\hline 5 & MNC05-835B-16 $6^{(1)}$ & $\begin{array}{l}\text { MNC00-599F-2 x } \\
\text { MNC99-537F-14-2 }\end{array}$ & Verde \\
\hline 6 & MNC05-841B-49(1) & $\begin{array}{l}\text { MNC00-599F-9 x } \\
\text { MNC99-537F-14-2 }\end{array}$ & Verde \\
\hline 7 & MNC05-847B-123(1) & $\begin{array}{l}\text { MNC00-599F-11 x } \\
\text { MNC99-537-14-2 }\end{array}$ & Verde \\
\hline 8 & MNC05-847B-126 & $\begin{array}{l}\text { MNC00-599F-11 x } \\
\text { MNC99-537-14-2 }\end{array}$ & Verde \\
\hline 9 & MNC99-541F-15 (1) & $\begin{array}{l}\text { TE93-210-13F x } \\
\text { TE96-282-22G }\end{array}$ & Branca \\
\hline 10 & BRS Guariba ${ }^{(2)}$ & $\begin{array}{c}\text { IT85F-2687 x } \\
\text { TE87-98-8G }\end{array}$ & Branca \\
\hline 11 & BRS Tumucumaque $^{(2)}$ & $\begin{array}{l}\text { TE96-282-22G x } \\
\text { IT87D-611-3 }\end{array}$ & Branca \\
\hline 12 & BRS Xiquexique(2) & $\begin{array}{l}\text { TE87-108-6G x } \\
\text { TE87-98-8G }\end{array}$ & Branca \\
\hline 13 & Paulistinha $^{(2)}$ & Juazeiro-CE & Canapu \\
\hline 14 & Vagem Roxa-THE(3) & Teresina-PI & Branca \\
\hline 15 & Azulão-MS ${ }^{(3)}$ & Dourados-MS & Azulão \\
\hline 16 & Sempre Verde-CE(3) & Fortaleza-CE & Sempre-verde \\
\hline
\end{tabular}

${ }^{(1)}$ Linhagem. ${ }^{(2)}$ Cultivar. ${ }^{(3)}$ Cultivar-testemunha.
$Y_{i j}=\mu+G_{i}+B_{j}+\varepsilon_{i j}$, em que: $\mu$ é a média geral; $\mathrm{G}_{\mathrm{i}}$ é o efeito do i-ésimo genótipo $(\mathrm{i}=1,2, \ldots, \mathrm{g}) ; \mathrm{B}_{\mathrm{j}}$ é o efeito do j-ésimo bloco $(\mathrm{j}=1,2, \ldots, \mathrm{r})$; e $\varepsilon_{\mathrm{ij}}$ é o erro experimental, com $\varepsilon_{\mathrm{iij}} \sim \mathrm{NID}\left(0, \sigma^{2}\right)$. Na análise de variância conjunta, utilizou-se $\mathrm{o}$ modelo $\mathrm{Y}_{\mathrm{ijk}}=\mu+\mathrm{G}_{\mathrm{i}}+\mathrm{A}_{\mathrm{j}}+\mathrm{GA}_{\mathrm{ij}}+\mathrm{B} / \mathrm{A}_{\mathrm{jk}}+\varepsilon_{\mathrm{ijk}}$, em que: $\mathrm{Y}_{\mathrm{ijk}}$ é a observação do i-ésimo genótipo, no k-ésimo bloco dentro do j-ésimo ambiente; $\mu$ é a média geral; $G_{i}$ é o efeito do i-ésimo genótipo $(\mathrm{i}=1,2, \ldots, \mathrm{g}) ; \mathrm{A}_{\mathrm{j}}$ é o efeito do j-ésimo ambiente $(\mathrm{j}=1,2, \ldots, a) ; \mathrm{GA}_{\mathrm{ij}}$ é o efeito da interação do i-ésimo genótipo com o j-ésimo ambiente; $\mathrm{B} / \mathrm{A}_{\mathrm{jk}}$ é o efeito do k-ésimo bloco dentro do j-ésimo ambiente; e $\varepsilon_{\mathrm{ijk}}$ é o erro experimental médio, $\operatorname{com} \varepsilon_{\mathrm{ij}} \sim \mathrm{NID}\left(0, \sigma^{2}\right)$.

Para cada caráter, estimaram-se os parâmetros genéticos coeficiente de variação genética $(\mathrm{CVg})$ e coeficiente b $(\mathrm{CVg} / \mathrm{CVe})$, em que $\mathrm{CVe}$ é o coeficiente de variação ambiental, conforme Cruz et al. (2004), para obtenção da variabilidade dos genótipos quanto aos caracteres avaliados. As médias dos genótipos foram agrupadas pelo teste de Scott-Knott, a 5\% de probabilidade. Todas as análises foram realizadas com o programa computacional Genes (Cruz, 2006).

\section{Resultados e Discussão}

Observaram-se diferenças significativas entre genótipos em relação à maioria dos caracteres, exceto quanto ao número de grãos por vagem verde (NGVV), em sequeiro, e quanto à produtividade de vagens verdes (PVV) e ao índice de grãos verdes (IGV), sob irrigação (Tabela 2). A variabilidade entre genótipos foi maior quanto aos caracteres número de dias para o início da floração (NDIF), comprimento da vagem verde (CVV), produtividade de vagens verdes (PVV) e produtividade de grãos verdes ( $\mathrm{PGV})$, em sequeiro. Em condições de irrigação, a variabilidade entre genótipos foi maior quanto aos caracteres NGVV e massa de 100 grãos verdes (M100GV), conforme as estimativas do coeficiente de variação genética $(\mathrm{CVg})$. Estes resultados são indicativos de que há possibilidade de seleção entre os genótipos quanto a esses caracteres, em ambas as condições de cultivo.

O menor efeito do ambiente sobre o fenótipo foi observado apenas nos caracteres IGV (sequeiro) e M100GV (irrigado), conforme estimativas do coeficiente b $(>1,0)$ (Tabela 2$)$. No entanto, os caracteres NGVV, em sequeiro; NDIF, com irrigação; 
e PVV, em ambas as condições, foram os caracteres mais influenciados pelo ambiente. Isso é indicativo de que maior sucesso será obtido com o melhoramento da relação grão verde/vagem verde e tamanho do grão verde.

O coeficiente de variação (CV) apresentou amplitude de $3,86 \%$ (NDIF) a $18,67 \%$ (PVV), em sequeiro, e de $4,48 \%$ (NDIF) a 26,40\% (PVV), sob irrigação, o que indica boa precisão experimental (Tabela 2). Esses valores de CV estão de acordo com os observados em outros estudos sobre o feijão-caupi, para a produção de feijão verde (Rocha et al., 2012 e Silva et al., 2013).

Diferenças quanto ao efeito de genótipos foram observadas em todos os caracteres, e diferenças quanto ao efeito de ambientes, na maioria dos caracteres (Tabela 3). Rocha et al. (2012), avaliaram um grupo de genótipos para produção do feijão verde e, também encontraram diferenças entre genótipos e entre os ambientes de sequeiro e de irrigação quanto a PGV. Isso evidencia a possibilidade de seleção e obtenção de ganhos para todos os caracteres, em ambas as condições de cultivo. A existência de diferenças entre ambientes indica que estes foram contrastantes quanto às condições de cultivo, principalmente em relação ao fator água.
Embora os ambientes de cultivo tenham diferido quanto aos caracteres NDIF, CVV, M100GV, PGV e IGV, o efeito da interação genótipo $\mathrm{x}$ ambiente não foi significativo para os caracteres (Tabela 3). A inexistência de interação genótipo $\mathrm{x}$ ambiente é uma indicação de que os genótipos apresentaram respostas previsíveis quanto aos caracteres em relação às variações ambientais/condições de cultivo.

Em razão das diferenças entre os ambientes, para a maioria dos caracteres (Tabela 3), as médias dos genótipos, para cada caráter, serão discutidas por ambiente (Tabela 4). Como não houve diferença entre genótipos quanto aos caracteres NGVV, em sequeiro, e PVV e IGV, sob irrigação (Tabela 2), não se aplicou o teste de Scott-Knott, nestes casos.

O caráter NDIF variou de 37 a 41 dias, em sequeiro, e de 42 a 47 dias sob irrigação (Tabela 4). As médias gerais, tanto em sequeiro (39 dias) quanto sob irrigação (43 dias), foram inferiores à média obtida por Silva et al. (2013), que avaliaram um grupo de genótipos de feijão-caupi para produção de feijão verde, sob irrigação, no Município de Serra Talhada, PE, e obtiveram média de 46 dias. Observou-se melhor discriminação entre genótipos, quanto ao NDIF com irrigação, em que os genótipos MNC00-303-09E,

Tabela 2. Resumos das análises de variância individuais e estimativas de parâmetros genéticos para os caracteres número de dias para o início da floração (NDIF), comprimento de vagem verde (CVV), número de grãos por vagem verde (NGVV), massa de cem grãos verdes (M100GV), produtividade de vagens verdes (PVV), produtividade de grãos verdes (PGV) e índice de grãos verdes (IGV), obtidos a partir da avaliação de 16 genótipos de feijão-caupi em condições de sequeiro e irrigação.

\begin{tabular}{|c|c|c|c|c|c|c|c|c|}
\hline Fonte de variação & GL & $\begin{array}{l}\text { NDIF } \\
\text { (dia) }\end{array}$ & $\begin{array}{l}\mathrm{CVV} \\
(\mathrm{cm}) \\
\end{array}$ & NGVV & $\begin{array}{c}\text { M100GV } \\
(\mathrm{g})\end{array}$ & $\begin{array}{c}\text { PVV } \\
\left(\mathrm{kg} \mathrm{ha}^{-1}\right)\end{array}$ & $\begin{array}{c}\text { PGV } \\
\left(\mathrm{kg} \mathrm{ha}^{-1}\right)\end{array}$ & $\begin{array}{l}\text { IGV } \\
(\%) \\
\end{array}$ \\
\hline & \multicolumn{8}{|c|}{ Ensaio em condição de sequeiro } \\
\hline Blocos & 3 & 0,66 & 1,51 & 0,78 & 32,50 & 356.092 & 230.784 & 0,002 \\
\hline Genótipos & 15 & $10,13^{* *}$ & $4,10^{* *}$ & $2,69^{\mathrm{ns}}$ & $113,30 * *$ & $1816.586^{* *}$ & $330.368 * *$ & $0,011 * *$ \\
\hline Resíduo & 45 & 2,26 & 1,06 & 1,54 & 18,25 & 460.245 & 122.355 & 0,001 \\
\hline$\overline{\mathrm{CV}}(\%)$ & & 3,86 & 4,49 & 8,21 & 10,33 & 18,67 & 17,87 & 6,79 \\
\hline $\operatorname{CVg}(\%)^{(1)}$ & & 3,49 & 3,92 & 2,62 & 9,92 & 7,95 & 9,47 & 7,59 \\
\hline $\mathrm{b}^{(2)}$ & & 0,90 & 0,87 & 0,31 & 0,96 & 0,42 & 0,53 & 1,13 \\
\hline \multirow[t]{2}{*}{ Média geral } & & 39,00 & 22,96 & 15,11 & 41,35 & 3.632 & 1.957 & 54,62 \\
\hline & \multicolumn{8}{|c|}{ Ensaio em condição de irrigação } \\
\hline Blocos & 3 & 14,06 & 2,15 & 0,36 & 75,47 & 456.124 & 262.014 & 0,043 \\
\hline Genótipos & 15 & $7,39 *$ & $2,65^{*}$ & $4,09 * *$ & $107,27 * *$ & $1.453 .365^{\mathrm{ns}}$ & $710.670 *$ & $0,010^{\text {ns }}$ \\
\hline Resíduo & 45 & 3,78 & 1.46 & 1,34 & 16,01 & 988.385 & 358.486 & 0,010 \\
\hline$\overline{\mathrm{CV}(\%)}$ & & 4,48 & 5,45 & 7,70 & 11,28 & 26,40 & 25,05 & 15,84 \\
\hline $\operatorname{CVg}(\%)^{(1)}$ & & 0,71 & 2,00 & 5,35 & 13,48 & 4,73 & 9,18 & - \\
\hline$b^{(2)}$ & & 0,16 & 0,36 & 0,68 & 1,20 & 0,18 & 0,38 & - \\
\hline Média geral & & 43,40 & 22,14 & 15,01 & 35,45 & 3.766 & 2.390 & 64,23 \\
\hline
\end{tabular}

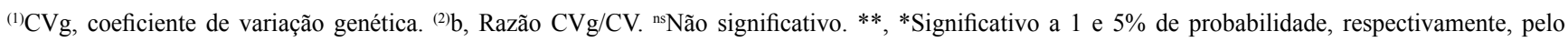
teste F. 
MNC05-847B-123 e Azulão-MS, distinguiram-se dos demais, por serem mais tardios. Em sequeiro, os genótipos MNC05-835B-16, MNC05-841B-49, MNC05-847B-123, MNC05-847B-126, BRS Guariba, BRS Tumucumaque e Vagem Roxa-THE, destacaramse dos demais quanto à precocidade, característica que se busca atualmente para o melhoramento de feijão-caupi. A diferença entre os NDIF dos tratamentos de sequeiro e irrigação foi de quatro dias. Isso resulta, provavelmente, das diferenças na ocorrência e distribuição de água no solo, no decorrer dos períodos de cultivo. A irrigação pode ter contribuído para aumentar os dias de floração nesta condição de cultivo.

A média do CVV variou de $21,01 \mathrm{~cm}$ a $25,13 \mathrm{~cm}$, em sequeiro, e de $20,59 \mathrm{~cm}$ a $23,67 \mathrm{~cm}$, sob irrigação, com média geral em torno de $22 \mathrm{~cm}$ em ambas as condições de cultivo (Tabela 4). Houve melhor discriminação dos genótipos relativa a esse caráter em sequeiro, com destaque para os genótipos MNC00-303-09E, Paulistinha e Sempre Verde-CE. Segundo Freire Filho (2011), o mercado de feijão-verde exige vagens grandes e atrativas. Assim, esses genótipos são os mais

Tabela 3. Resumo da análise de variância conjunta para os caracteres número de dias para o início da floração (NDIF), comprimento de vagem verde (CVV), número de grãos por vagem verde (NGVV), massa de cem grãos verdes (M100GV), produtividade de vagens verdes (PVV), produtividade de grãos verdes (PGV) e índice de grãos verdes (IGV), obtido a partir da avaliação de 16 genótipos de feijão-caupi em dois ambientes (sequeiro e irrigado).

\begin{tabular}{|c|c|c|c|c|c|c|c|c|}
\hline Fonte de variação & $\mathrm{GL}$ & $\begin{array}{l}\text { NDIF } \\
\text { (dia) }\end{array}$ & $\begin{array}{l}\text { CVV } \\
(\mathrm{cm})\end{array}$ & NGVV & $\begin{array}{c}\text { M100GV } \\
(\mathrm{g})\end{array}$ & $\begin{array}{c}\text { PVV } \\
\left(\mathrm{kg} \mathrm{ha}^{-1}\right)\end{array}$ & $\begin{array}{c}\text { PGV } \\
\left(\mathrm{kg} \mathrm{ha}^{-1}\right)\end{array}$ & $\begin{array}{l}\text { IGV } \\
(\%) \\
\end{array}$ \\
\hline Blocos/Ambientes & 6 & 7,36 & 1,83 & 0,57 & 53,99 & 406.108 & 246.399 & 0,023 \\
\hline Genótipos (G) & 15 & $13,43 *$ & $5,43 *$ & $5,73 * *$ & $201,47^{*}$ & $2.379 .917 * *$ & $747.506^{* *}$ & 0,017 * \\
\hline Ambientes (A) & 1 & $621,28 * *$ & $21,33^{*}$ & $0,28 \mathrm{~ns}$ & $1.114,45^{*}$ & $570.858^{\text {ns }}$ & $6.002 .532 *$ & $0,293 *$ \\
\hline $\mathrm{G} \times \mathrm{A}$ & 15 & $4,10^{\mathrm{ns}}$ & $1,30^{\mathrm{ns}}$ & $1,05^{\mathrm{ns}}$ & $19,10^{\text {ns }}$ & $890.034^{\mathrm{ns}}$ & $293.532^{\mathrm{ns}}$ & $0,004^{\mathrm{ns}}$ \\
\hline Resíduo & 90 & 3,02 & 1,26 & 1,43 & 17,13 & 724.315 & 240.420 & 0,009 \\
\hline
\end{tabular}

ns Não significativo. ${ }^{* *}$, *Significativo a 1 e $5 \%$ de probabilidade, respectivamente, pelo teste $\mathrm{F}$.

Tabela 4. Estimativas de médias por ambiente, para os caracteres número de dias para o início da floração (NDIF), comprimento de vagem verde (CVV), número de grãos por vagem verde (NGVV), massa de cem grãos verdes (M100GV), produtividade de vagens verdes (PVV), produtividade de grãos verdes (PGV) e índice de grãos verdes (IGV), obtidas a partir da avaliação de 16 genótipos de feijão-caupi em dois ambientes (S, sequeiro; I, irrigado) ${ }^{(1)}$.

\begin{tabular}{|c|c|c|c|c|c|c|c|c|c|c|c|c|c|c|}
\hline \multirow[t]{2}{*}{ Genótipo } & \multicolumn{2}{|c|}{ NDIF (dia) } & \multicolumn{2}{|c|}{ CVV $(\mathrm{cm})$} & \multicolumn{2}{|c|}{ NGVV } & \multicolumn{2}{|c|}{ M100GV (g) } & \multicolumn{2}{|c|}{ PVV $\left(\mathrm{kg} \mathrm{ha}^{-1}\right)$} & \multicolumn{2}{|c|}{ PGV $\left(\mathrm{kg} \mathrm{ha}^{-1}\right)$} & \multicolumn{2}{|c|}{ IGV (\%) } \\
\hline & $\mathrm{S}$ & I & $\mathrm{S}$ & $\mathrm{I}$ & $\mathrm{S}$ & $\mathrm{I}$ & $\mathrm{S}$ & $\mathrm{I}$ & $\mathrm{S}$ & $\mathrm{I}$ & $\mathrm{S}$ & $\mathrm{I}$ & $\mathrm{S}$ & $\mathrm{I}$ \\
\hline $1, \mathrm{MNC} 00-303-09 \mathrm{E}$ & $40 \mathrm{a}$ & $45,75 \mathrm{a}$ & $24,20 \mathrm{a}$ & $22,59 a$ & 15,35 & $14,45 b$ & $47,49 a$ & $40,99 a$ & $4.266 \mathrm{~b}$ & 3.852 & $1.965 \mathrm{a}$ & $2.139 a$ & $46 c$ & 56 \\
\hline 2, MNC00-595F-2 & $40 \mathrm{a}$ & $43,25 b$ & $22,96 b$ & $23,13 \mathrm{a}$ & 15,55 & $15,50 \mathrm{a}$ & $41,29 b$ & $35,60 \mathrm{a}$ & $3.869 \mathrm{~b}$ & 3.725 & $1.972 \mathrm{a}$ & $2.382 \mathrm{a}$ & $51 b$ & 65 \\
\hline 3, MNC00-595F-27 & $41 \mathrm{a}$ & $43,25 b$ & $23,20 \mathrm{~b}$ & $21,86 b$ & 15,05 & $15,25 \mathrm{a}$ & $37,75 b$ & $30,25 b$ & $4.348 b$ & 5.319 & $2.272 \mathrm{a}$ & $3.322 \mathrm{a}$ & $53 b$ & 64 \\
\hline 4, MNC05-835B-15 & $39 a$ & $43,25 b$ & $22,27 b$ & $20,59 b$ & 14,20 & $13,10 \mathrm{~b}$ & $36,02 b$ & $31,43 b$ & $2.842 \mathrm{c}$ & 3.982 & $1.439 b$ & $2.298 \mathrm{a}$ & $50 \mathrm{~b}$ & 60 \\
\hline 5, MNC05-835B-16 & $37 b$ & $42,00 b$ & $22,30 \mathrm{~b}$ & $22,45 \mathrm{a}$ & 14,05 & $13,55 b$ & $37,46 b$ & $36,12 \mathrm{a}$ & $3.515 \mathrm{c}$ & 4.021 & $1.889 \mathrm{a}$ & $2.365 \mathrm{a}$ & $54 b$ & 59 \\
\hline $6, \mathrm{MNC} 05-841 \mathrm{~B}-49$ & $38 b$ & $43,25 b$ & $22,75 b$ & $21,61 b$ & 15,55 & $15,50 \mathrm{a}$ & $40,07 b$ & $28,90 b$ & $3.871 b$ & 3.784 & $2.266 \mathrm{a}$ & $2.599 \mathrm{a}$ & $58 \mathrm{a}$ & 69 \\
\hline 7, MNC05-847B-123 & $38 b$ & $44,50 \mathrm{a}$ & $21,01 b$ & $21,19 b$ & 13,85 & $13,65 b$ & $39,67 b$ & $35,92 \mathrm{a}$ & $3.231 \mathrm{c}$ & 4.250 & $1.882 \mathrm{a}$ & $2.926 \mathrm{a}$ & $58 \mathrm{a}$ & 67 \\
\hline 8, MNC05-847B-126 & $38 b$ & $42,00 \mathrm{~b}$ & $21,71 b$ & $21,37 \mathrm{~b}$ & 14,55 & $14,85 b$ & $36,39 b$ & $28,24 b$ & $3.142 \mathrm{c}$ & 3.942 & $1.712 \mathrm{~b}$ & $2.799 \mathrm{a}$ & $54 b$ & 74 \\
\hline 9, MNC99-541F-15 & $39 a$ & $43,25 b$ & $22,61 b$ & $21,54 b$ & 14,85 & $15,00 \mathrm{a}$ & $40,18 b$ & $40,66 \mathrm{a}$ & $3.346 \mathrm{c}$ & 3.451 & $2.062 \mathrm{a}$ & $2.390 \mathrm{a}$ & $62 \mathrm{a}$ & 69 \\
\hline 10, BRS Guariba & $37 b$ & $43,25 b$ & $23,37 b$ & $22,74 a$ & 15,15 & $14,60 \mathrm{~b}$ & $43,85 \mathrm{a}$ & $39,52 \mathrm{a}$ & $3.786 \mathrm{~b}$ & 3.796 & $2.234 \mathrm{a}$ & $2.492 \mathrm{a}$ & $59 a$ & 65 \\
\hline 11, BRS Tumucumaque & $37 \mathrm{~b}$ & $42,00 \mathrm{~b}$ & $23,70 \mathrm{~b}$ & $22,41 \mathrm{a}$ & 14,55 & $14,50 \mathrm{~b}$ & $48,49 a$ & $42,29 \mathrm{a}$ & $3.856 \mathrm{~b}$ & 4.052 & $3.217 \mathrm{a}$ & $2.749 \mathrm{a}$ & $60 \mathrm{a}$ & 68 \\
\hline 12, BRS Xiquexique & $41 \mathrm{a}$ & $43,25 b$ & $22,85 b$ & $21,92 b$ & 16,00 & $16,75 \mathrm{a}$ & $40,00 \mathrm{~b}$ & $30,33 b$ & $3.368 \mathrm{c}$ & 3.424 & $1.930 \mathrm{a}$ & $2.148 \mathrm{a}$ & $58 \mathrm{a}$ & 62 \\
\hline 13, Paulistinha & $41 \mathrm{a}$ & $43,25 b$ & $25,13 \mathrm{a}$ & $22,85 \mathrm{a}$ & 16,20 & $15,50 \mathrm{a}$ & $49,95 \mathrm{a}$ & $41,54 \mathrm{a}$ & $3.335 \mathrm{c}$ & 3.059 & $1.755 b$ & $1.908 \mathrm{a}$ & $54 b$ & 65 \\
\hline 14, Vagem Roxa-THE(2) & $37 b$ & $42,00 \mathrm{~b}$ & $22,36 b$ & $21,58 \mathrm{~b}$ & 16,70 & $15,90 \mathrm{a}$ & $30,48 b$ & $27,91 b$ & $2.349 \mathrm{c}$ & 2.678 & $1.382 b$ & $1.677 \mathrm{a}$ & $59 a$ & 61 \\
\hline 15, Azulão-MS ${ }^{(2)}$ & $41 \mathrm{a}$ & $47,00 \mathrm{a}$ & $23,05 b$ & $23,67 \mathrm{a}$ & 14,40 & $16,30 \mathrm{a}$ & $46,86 a$ & $39,25 \mathrm{a}$ & $5.301 \mathrm{a}$ & 3.946 & $2.297 \mathrm{a}$ & $2.109 \mathrm{a}$ & $43 c$ & 55 \\
\hline 16, Sempre Verde-CE ${ }^{(2)}$ & $40 \mathrm{a}$ & $43,25 b$ & $24,39 \mathrm{a}$ & $22,78 \mathrm{a}$ & 15,75 & $15,85 \mathrm{a}$ & $45,66 \mathrm{a}$ & $38,22 \mathrm{a}$ & $3.686 \mathrm{~b}$ & 2.967 & $1.935 \mathrm{a}$ & $1.935 \mathrm{a}$ & $53 b$ & 67 \\
\hline Média geral & 39,00 & 43,40 & 22,95 & $22,14 \mathrm{~A}$ & 15,11 & 15,02 & 41,35 & 35,45 & 3.632 & 3.766 & 1.957 & 2.390 & 55 & 64 \\
\hline
\end{tabular}

${ }^{(1)}$ Médias seguidas por letras iguais, nas colunas, pertencem a um mesmo grupo, pelo teste de Scott-Knott, a 5\% de probabilidade. ${ }^{(2)}$ Testemunha. 
indicados em termos de tamanho de vagem para esse mercado.

O caráter M100GV variou de 30,48 g a 49,95 g, em sequeiro, e de 27,91 g a 42,29 g sob irrigação, com média geral de $41,35 \mathrm{~g}$ em sequeiro e de $35,45 \mathrm{~g}$ sob irrigação (Tabela 4). O maior tamanho de grão, obtido em sequeiro, foi superior ao das médias obtidas por Silva et al. (2013), que foram, respectivamente, de 36 e 35 g, sob irrigação. Foram distinguidos dois grupos de genótipos, a e b, respectivamente, como os genótipos de maior e menor tamanho de grão. Seis genótipos foram superiores quanto ao tamanho do grão (MNC00-303-09E, BRS Guariba, BRS Tumucumaque, Paulistinha, Azulão-MS e Sempre Verde-CE), portanto, os de maior potencial para o mercado de feijão verde, em que o consumidor tem maior preferência pelos genótipos de grãos maiores.

O caráter PVV apresentou média de $2.349 \mathrm{~kg} \mathrm{ha}^{-1}$ a $5.300 \mathrm{~kg} \mathrm{ha}^{-1}$, em sequeiro, e de $2.667 \mathrm{~kg} \mathrm{ha}^{-1}$ a $5.319 \mathrm{~kg} \mathrm{ha}^{-1}$, sob irrigação, com média geral de $3.632 \mathrm{~kg} \mathrm{ha}^{-1}$ em sequeiro e de $3.765 \mathrm{~kg} \mathrm{ha}^{-1} \mathrm{sob}$ irrigação (Tabela 4). Essas médias foram superiores à encontrada por Rocha et al. (2012), de $2.109 \mathrm{~kg} \mathrm{ha}^{-1}$, em um estudo com feijão verde sob irrigação. Houve discriminação dos genótipos somente em sequeiro, em que se distinguiram três grupos de genótipos - a, b e c-, respectivamente, com genótipos de maior, intermediária e menor PVV, em que se destacou a cultivar Azulão-MS com a maior média. Em valor absoluto, a maior média sob irrigação, com $5.319 \mathrm{~kg} \mathrm{ha}^{-1}$, foi observada na linhagem MNC00-595F-27.

A PGV apresentou média de $1.381 \mathrm{~kg} \mathrm{ha}^{-1}$ a $3.217 \mathrm{~kg} \mathrm{ha}^{-1}$, em sequeiro, e de $1.677 \mathrm{~kg} \mathrm{ha}^{-1} \mathrm{a}$ $3.322 \mathrm{~kg} \mathrm{ha}^{-1}$, sob irrigação, com média geral de $1.956 \mathrm{~kg} \mathrm{ha}^{-1}$ em sequeiro e de $2.389 \mathrm{~kg} \mathrm{ha}^{-1}$ com irrigação (Tabela 4). Ramos et al. (2012) e Rocha et al. (2012) avaliaram genótipos de feijão-caupi para a produção de feijão verde, sob irrigação, em Teresina, PI, e obtiveram, respectivamente, médias abaixo (1.846 kg ha-1) e acima (2.715 $\mathrm{kg} \mathrm{ha}^{-1}$ ) das encontradas no presente trabalho; no entanto, esta última média foi obtida a partir de um estudo com duas cultivares. Houve discriminação dos genótipos somente em sequeiro, em que se distinguiram dois grupos de genótipos, a e b, respectivamente, como os genótipos de maior e menor PGV, dos quais 12 foram superiores (Tabela 4). Em valor absoluto, as maiores médias de PGV foram obtidas pela cultivar BRS Tumucumaque (3.217 $\left.\mathrm{kg} \mathrm{ha}^{-1}\right)$ e pela linhagem
MNC00-595F-27 (2.272 $\left.\mathrm{kg} \mathrm{ha}^{-1}\right)$, respectivamente em sequeiro e irrigação.

O caráter IGV variou de 43,5 a $62 \%$, em sequeiro, e de 55 a 74\%, sob irrigação, com média geral de 55\% em sequeiro e $64 \%$ sob irrigação (Tabela 4). A maior média foi superior à encontrada por Rocha et al. (2012), de 52,6\%, em um estudo da adaptabilidade e estabilidade de genótipos de feijão-caupi quanto à produção de grãos frescos, em Teresina, PI, e por Silva et al. (2013), de 57,7\%, em cultivares de feijão-caupi avaliadas quanto à produção de grãos verdes em Serra Talhada, PE - ambos os estudos de tratamentos sob irrigação. Houve discriminação dos genótipos somente em sequeiro, em que foram distinguidos três grupos de genótipos ( $\mathrm{a}, \mathrm{b}$ e c), respectivamente, como genótipos de maior, intermediário e menor IGV, dos quais sete genótipos foram superiores. Isso pode ser explicado como decorrência da irrigação, que favoreceu a maior relação grão/casca, característica que se busca para o mercado de feijão verde.

A cultivar-testemunha Azulão-MS foi a primeira colocada em PVV e a segunda em PGV, em sequeiro, provavelmente pelo fato de apresentar índice menor de grãos (Tabela 4). Isso indica que a relação grão verde/ vagem verde desta cultivar é baixa, o que é um fator negativo para a comercialização.

A linhagem MNC00-595F-27, em sequeiro, apesar de não ter superado as melhores testemunhas quanto à PVV ('Azulão-MS') e à PGV ('BRS Tumucumaque'), foi a segunda e terceira colocada, quanto a esses caracteres, respectivamente, entre todos os genótipos; sob irrigação, não diferiu das testemunhas, mas foi a primeira colocada para ambos os caracteres (Tabela 4). Além disso, ressalta-se que essa linhagem pertence à subclasse comercial verde (Tabela 1), com tegumento e cotilédone verdes, aspecto que confere maior capacidade de preservação da cor verde pós-colheita do que as demais subclasses comerciais. Isso é um indicativo de que, entre as linhagens, esta apresenta maior potencial para o mercado de feijão verde.

\section{Conclusões}

1. Os genótipos de feijão-caupi apresentam maior variabilidade genética quanto aos caracteres massa de cem grãos verdes e produtividade de grãos verdes, em sequeiro e irrigação.

2. Os genótipos sob irrigação apresentam comportamento produtivo similar ao das testemunhas.

Pesq. agropec. bras., Brasília, v.50, n.5, p.392-398, maio 2015 DOI: $10.1590 / \mathrm{S} 0100-204 X 2015000500006$ 
3. A cultivar Azulão-MS apresenta potencial para a produtividade de vagens verdes em sequeiro, porém, baixa relação grão verde/vagem verde.

4. A cultivar BRS Tumucumaque apresenta potencial para a produtividade de grãos verdes em sequeiro, enquanto a linhagem MNC00-595F-27 o apresenta em condições de irrigação.

\section{Agradecimentos}

À Coordenação de Aperfeiçoamento de Pessoal de Nível Superior (Capes), pela concessão de bolsa; À Embrapa Meio-Norte, pela disponibilização da área experimental e infraestrutura para a condução da pesquisa; e aos funcionários do setor de melhoramento de feijão-caupi, pelo auxílio na condução dos experimentos.

\section{Referências}

ANDRADE, F.N.; ROCHA, M. de M.; GOMES, R.L.F.; FREIRE FILHO, F.R.; RAMOS, S.R.R. Estimativas de parâmetros genéticos em genótipos de feijão-caupi avaliados para feijão fresco. Revista Ciência Agronômica, v.41, p.253-258, 2010. DOI: 10.1590/ S1806-66902010000200012.

BENEVIDES, C.M. de J.; SOUZA, R.D.B.; SOUZA, M.V. de; LOPES, M.V. Efeito do processamento sobre os teores de oxalato e tanino em maxixe (Cucumis anguria L.), jiló (Solanum gilo), feijão verde (Vigna unguiculata (L.) Walp.) e feijão-andu (Cajanus cajan (L.) Mill sp.). Alimentos e Nutrição, v.24, p.321-327, 2013.

CRUZ, C.D. Programa genes: biometria. Viçosa: Ed. UFV, 2006. $382 \mathrm{p}$.

CRUZ, C.D.; REGAZZI, A.J.; CARNEIRO, P.C.S. Modelos biométricos aplicados ao melhoramento genético. 3.ed. Viçosa: Ed. UFV, 2004. v.1, 480p.

FREIRE-FILHO, F.R.; CHAMBLISS, O.L.; HUNTER, A.G. Crossing potential in the production of persistent green seeds in Cowpea using gt and gc genes. Crop Breeding and Applied Biotechnology, v.2, p.205-212, 2002. DOI: 10.12702/1984-7033. v02n02a06.

FREIRE FILHO, F.R. (Ed.). Feijão-caupi no Brasil: produção, melhoramento genético, avanços e desafios. Teresina: Embrapa Meio-Norte, 2011. 84p.
FREIRE FILHO, F.R.; ROCHA, M. de M.; RIBEIRO, V.Q.; RAMOS, S.R.R.; MACHADO, C. de F. Novo gene produzindo cotilédone verde em feijão-caupi. Revista Ciência Agronômica, v.38, p.286-290, 2007.

FURTUNATO, A.A.; MAGALHÃES, M.M. dos A.; MARIA, Z.L. Estudo do feijão verde (Vigna unguiculata (L.) Walp.) minimamente processado. Ciência e Tecnologia de Alimentos, v.20, p.299-301, 2000. DOI: 10.1590/S0101-20612000000300004.

LIMA, E.D.P. de A.; JERÔNIMO, E. de S.; LIMA, C.A. de A.; GONDIM, P.J. de S.; ALDRIGUE, M.L.; CAVALCANTE, L.F. Características físicas e químicas de grãos verdes de linhagens e cultivares de feijão-caupi para processamento tipo conserva. Revista Brasileira de Engenharia Agrícola e Ambiental, v.7, p.129-134, 2003. DOI: 10.1590/S1415-43662003000100021.

LIMA, N.L.; EMANUELLE, C.; SILVA, C.L. da; DINIZ, M. do C.; OLIVEIRA, M.R.T. de; GADELHA, T.S. Estudo sobre a conservação de quatro variedades de feijão macassar verde (Vigna unguiculata (L.) Walp.): submetidos a temperaturas de refrigeração e congelamento. Revista Brasileira de Produtos Agroindustriais, v.2, p.57-69, 2000.

RAMOS, H.M.M.; BASTOS, E.A.; ANDRADE JÚNIOR, A.S. de; MAROUELLI, W.A. Estratégias ótimas de irrigação do feijão-caupi para produção de grãos verdes. Pesquisa Agropecuária Brasileira, v.47, p.576-583, 2012. DOI: 10.1590/ S0100-204X2012000400014.

ROCHA, M. de M.; ANDRADE, F.N.; GOMES, R.L.F.; FREIRE FILHO, F.R.; RAMOS, S.R.R.; RIBEIRO, V.Q. Adaptabilidade e estabilidade de genótipos de feijão-caupi quanto à produção de grãos frescos, em Teresina-PI. Revista Científica Rural, v.14, p.40-55, 2012.

SALGADO, S.M.; MELO FILHO, A.B. de; ANDRADE, S.A.C.; MACIEL, G.R.; LIVERA, A.V.S.; GUERRA, N.B. Modificação da concentração de amido resistente em feijão macassar (Vigna unguiculata (L.) Walp.) por tratamento hidrotérmico e congelamento. Ciência e Tecnologia de Alimentos, v.25, p.259-264, 2005. DOI: 10.1590/S0101-20612005000200013.

SILVA, E.F.; BARROS-JÚNIOR, A.P.; SILVEIRA, L.M. da; SANTANA, F.M. de S.; SANTOS, M.G. dos. Avaliação de cultivares de feijão-caupi irrigado para produção de grãos verdes em Serra Talhada-PE. Revista Caatinga, v.26, p.21-26, 2013.

SOUZA, C.L.C. de; LOPES, A.C. de A.; GOMES, R.L.F.; ROCHA, M. de M.; SILVA, E.M. Variability and correlations in cowpea populations for green-grain production. Crop Breeding and Applied Biotechnology, v.7, p.262-269, 2007. DOI: 10.12702/1984-7033.v07n03a05.

Recebido em 6 de outubro de 2014 e aprovado em 12 de março de 2015

Pesq. agropec. bras., Brasília, v.50, n.5, p.392-398, maio 2015

DOI: $10.1590 / \mathrm{S} 0100-204 X 2015000500006$ 